\title{
Risk Factors for Tumor Size Increase During Active Surveillance of Papillary Thyroid Cancer: Meta-Analysis and Systematic Review
}

\author{
Doh Young Lee ${ }^{(D)}$ and Pilkeun Jang ${ }^{(D)}$ \\ Department of Otorhinolaryngology-Head and Neck Surgery, Seoul National University Boramae Medical Center, \\ Seoul National University College of Medicine, Seoul, Korea
}

\author{
갑상선 유두암의 적극적 감시에서 종양 크기 증가의 위험 인자에 대한 체계적 문헌 고찰 및 메타 분석 \\ 이도영 · 장필근 \\ 서울대학교 의과대학 보라매병원 이비인후과학교실
}

\author{
Received October 20, 2021 \\ Revised October 30, 2021 \\ Accepted November 1, 2021 \\ Address for correspondence \\ Doh Young Lee, MD, PhD \\ Department of Otorhinolaryngology- \\ Head and Neck Surgery, \\ Seoul National University \\ Boramae Medical Center, \\ Seoul National University \\ College of Medicine, \\ 20 Boramae-ro 5-gil, Dongjak-gu, \\ Seoul 07061, Korea \\ Tel $+82-2-870-2444$ \\ Fax $+82-2-870-3863$ \\ E-mail dohyoungishere@gmail.com
}

Background and Objectives The purpose of this study was to systematically review literatures on active surveillance for low-risk differentiated thyroid cancer, and to evaluate risk factors for tumor size increase during active surveillance.

Subjects and Method We conducted a systematic review and meta-analysis of studies reporting on tumor growth during active surveillance of papillary thyroid cancer. Using the MEDLINE and EMBASE databases, we searched studies published from the inception of database to December 2020. Studies were included if reported on at least one clinical risk parameter in addition to reporting on the change in tumor size during active surveillance.

Results Out of 33 studies screened, seven were included in the meta-analysis. The odds ratio of a temporal size increase of more than $3 \mathrm{~mm}$ in papillary thyroid cancer was 0.011 person-years ( $95 \%$ confidence interval [CI]: 0.009 to 0.013 ). The odds ratio of lymph node metastasis was 0.002 person-years (95\% CI: 0.001 to 0.003$)$. Younger age was a significant risk factor for tumor growth during active surveillance, with a standardized median difference of -0.63 (95\% CI: -1.00 to -0.27$)$. In the three studies that evaluated the association of thyroidstimulating hormone levels and tumor size, the results were contradictory.

Conclusion Active surveillance may be used more cautiously for younger patients. Korean J Otorhinolaryngol-Head Neck Surg 2021;64(12):914-21

Keywords Active surveillance; Meta-analysis; Risk; Thyroid cancer.

\section{Introduction}

The worldwide incidence of thyroid cancer has rapidly raised, and approximately 289000 individuals are diagnosed with thyroid cancer annually. ${ }^{1)}$ In addition, thyroid cancer incidence is rising at a higher rate than the incidence of any other type of cancer. ${ }^{2)}$ Most thyroid cancers are well-differenti-

This is an Open Access article distributed under the terms of the Creative Commons Attribution Non-Commercial License (https://creativecommons.org/licenses/by-nc/4.0) which permits unrestricted non-commercial use, distribution, and reproduction in any medium, provided the original work is properly cited. ated localized tumors of less than $2 \mathrm{~cm}$ in diameter with a low risk of metastases. ${ }^{3-6)}$ Postoperative quality of life after thyroidectomies is as important as disease control, because of the low mortality rate associated with papillary thyroid carcinoma.

Since Ito, et al. ${ }^{7)}$ reported on active surveillance of differentiated thyroid cancer, several guidelines have suggested observation as an effective alternative to surgery and a means of reducing the unnecessary morbidity resulting from the operation. ${ }^{8)}$ The National Cancer Institute defines active surveillance as "a treatment plan that involves closely watching a 
patient's condition but not giving any treatment unless there are changes in test results that show the condition is getting worse." In low risk malignancies, the purpose of active surveillance is, in part, to avoid overtreatment and minimize treatment-related morbidity, particularly for individuals whose disease is not likely to limit survival and does not rapidly progress. ${ }^{9}$

Although several studies provide evidence for this approach, a comprehensive analysis is lacking. Moreover, there is a need for accurate information for patients themselves and their guardians to support decision-making. Treatment recommendations should be based on investigations into risk factors of substantial change. As such, a review of evidence regarding thyroid cancer management accumulated to date is necessary. The objective of this study was to systematically review the published English-language literature on primary active surveillance for low-risk differentiated thyroid cancer, and to evaluate the risk factors of size increase during active surveillance.

\section{Subjects and Methods}

This systematic review followed the PRISMA checklist (Supplementary Table 1). ${ }^{10)}$ It used a PRISMA Flow Diagram to describe the flow of information through the different phases of the systematic review. ${ }^{11)}$ This study used qualitative and quantitative methods to examine reasons for variation in prevalence estimates.

\section{Selection criteria}

Two of the authors (DYL and PJ) independently searched the MEDLINE and EMBASE databases for articles published from database inception to December 2020 reporting on the active surveillance of thyroid cancer. We used the following terms for the literature search: ("thyroid" AND ("surveillance" OR “observation")). Two authors independently screened the titles and abstracts. We agreed on a final list, with discrepancies resolved by a common consensus.

\section{Inclusion and exclusion criteria}

The inclusion criteria for the current meta-analysis were as follows: 1) report of at least one risk factor (age, sex, etc.) and rates of size increase in low-risk papillary thyroid cancer in each risk group. We defined low-risk papillary thyroid cancer as T1a or T1b disease (i.e., primary tumor less than $2 \mathrm{~cm}$ in diameter) where disease is localized to the thyroid clinically and radiologically; 2) original articles from peer-reviewed scientific journals published in English; and 3) studies with adult patients aged over 18 years. Studies were excluded if they met one of the following criteria: 1) in vitro studies, animal studies, case reports, review articles, and abstracts; 2) lack of approachability to original articles (e.g., only abstracts) and/or incomplete data; and 3) duplicate publications.

\section{Data extraction and statistical analysis}

Two researchers (DYL and PJ) reviewed all studies independently and performed data extraction; they resolved any discrepancies by reaching consensus between the two authors. For each article that reported risk factors of size increase of thyroid cancer, the following information was noted: author, year of publication, number of patients, and incidence of size increase in those with risk factors. We analyzed pooled proportions, while cases of incomplete or missing information were excluded. Weighted proportions and their 95\% confidence intervals (CIs) for the percentage of age, sex, hearing loss, and initial tumor size were calculated.

We used both random-effects model and fixed effects model meta-analysis. Random effects models were applied when the heterogeneity test based on the Cochran Q test and $\mathrm{I}^{2}$ statistic (for the percentage of overall variation) revealed that studies were inconsistent. We considered $p$-values $<0.01$ for the Cochran Q test to indicate significant heterogeneity among studies. Since the $\mathrm{I}^{2}$ statistic describes the percentage of total variation across studies due to heterogeneity rather than chance, $\mathrm{I}^{2}<25 \%, \mathrm{I}^{2}=25 \%$ to $50 \%$, and $\mathrm{I}^{2}>50 \%$ represented low, moderate, and high heterogeneity, respectively. ${ }^{12)}$ The publication bias was assessed using funnel plots. ${ }^{13)}$ The analyses were performed using the software package $\mathrm{R}$ for Windows, version 3.3.2 (R Foundation for Statistical Computing).

\section{Results}

\section{Characteristics of the studies}

A diagram showing the flow of studies from initial identification, through reasons for exclusion, to final selection is shown in Supplementary Table 2 and Fig. 1. We initially identified 11793 articles and the search identified 353 abstracts after title screening and removing the duplicate, of which 33 appeared to meet the initial screening criteria. After reviewing the full-length articles, we excluded 23 studies owing to the following reasons: duplicate cohorts $(n=7)$, confounders in analysis $(n=3)$, review article $(n=12)$, and research letter $(n=1)$. Seven studies ${ }^{7,12,14-18)}$ met all inclusion criteria of this system- 
atic review; all included studies were prospective observational studies published between 2014 and 2020 (Table 1). The risk of bias of the studies included in the qualitative review was assessed based on Newcastle-Ottawa Scale criteria (Supplementary Table 3), and all of the studies demonstrated the appropriate quality for meta-analysis.

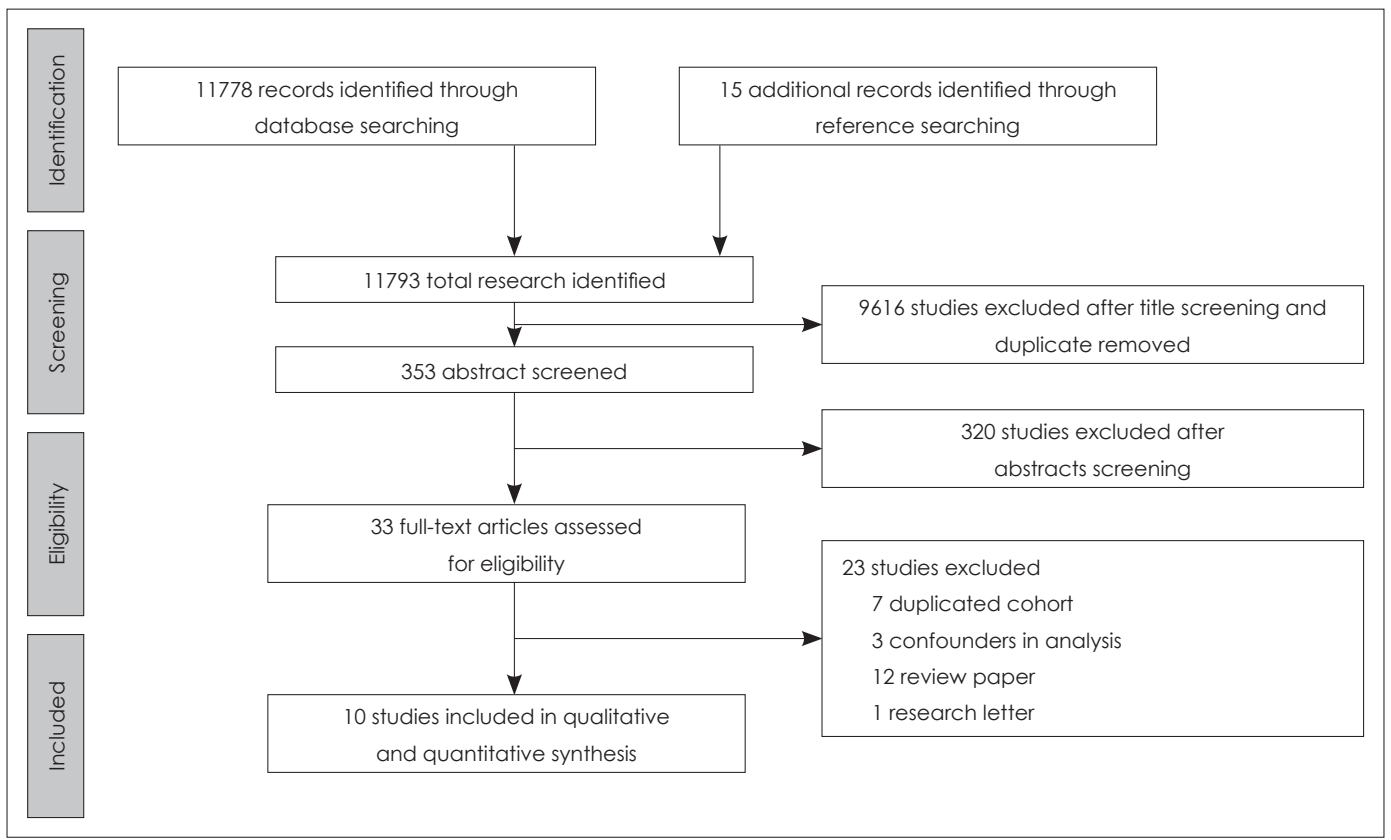

Fig. 1. Search flow chart (PRISMA flow diagram).

Table 1. Studies included in quantitative analysis

\begin{tabular}{|c|c|c|c|c|c|c|c|}
\hline $\begin{array}{l}\text { Author } \\
\text { (year) }\end{array}$ & Nationality & Inclusion criteria & $\begin{array}{l}\text { Follow-up } \\
\text { duration }\end{array}$ & $\begin{array}{l}\text { Number } \\
\text { of } \\
\text { patients }\end{array}$ & $\begin{array}{c}\text { Size } \\
\text { criteria }\end{array}$ & $\begin{array}{l}\text { Number } \\
\text { of patients } \\
\text { with size } \\
\text { increase } \\
(>3 \mathrm{~mm})\end{array}$ & $\begin{array}{l}\text { Number } \\
\text { of patients } \\
\text { with LNM }\end{array}$ \\
\hline $\begin{array}{l}\text { Ito, et al.7) } \\
(2014)^{*}\end{array}$ & Japan & $\begin{array}{l}<10 \text { mm in size } \\
\text { PTC (cytology) }\end{array}$ & $\begin{array}{r}60 \text { months } \\
(18-227)\end{array}$ & 1235 & $\begin{array}{l}3 \mathrm{~mm} \text { in maximal } \\
\text { diameter }\end{array}$ & 58 & 19 \\
\hline $\begin{array}{l}\text { Sugitani, et al. }{ }^{14)} \\
(2014)^{*}\end{array}$ & Japan & $\begin{array}{l}<10 \text { mm in size } \\
\text { PTC (cytology) }\end{array}$ & $\begin{array}{l}6.5 \text { years } \\
(2-22)\end{array}$ & 415 & $\begin{array}{l}3 \mathrm{~mm} \text { in maximal } \\
\text { diameter }\end{array}$ & 25 & 3 \\
\hline $\begin{array}{l}\text { Kwon, et al. }{ }^{16)} \\
(2017)\end{array}$ & South Korea & $\begin{array}{l}<10 \mathrm{~mm} \text { in size } \\
\text { PTC (cytology) }\end{array}$ & $\begin{array}{r}30.1 \text { months } \\
(21.4-43.7)\end{array}$ & 192 & $\begin{array}{l}3 \mathrm{~mm} \text { in maximal } \\
\text { diameter }\end{array}$ & 27 & 1 \\
\hline $\begin{array}{l}\text { Tuttle, et al. }{ }^{15)} \\
(2017)\end{array}$ & USA & $\begin{array}{l}<15 \mathrm{~mm} \text { in size } \\
\text { Suspicious for malignancy } \\
\text { or malignant (cytology) }\end{array}$ & $\begin{array}{l}25 \text { months } \\
(6-166)\end{array}$ & 291 & $\begin{array}{l}3 \mathrm{~mm} \text { in maximal } \\
\text { diameter }\end{array}$ & 11 & 0 \\
\hline $\begin{array}{l}\text { Oh, et al. }{ }^{19)} \\
(2018)\end{array}$ & South Korea & $\begin{array}{l}<10 \mathrm{~mm} \text { in size } \\
\text { Suspicious for malignancy } \\
\text { or malignant (cytology) }\end{array}$ & $\begin{array}{r}34.1 \text { months } \\
(23.6-47.0)\end{array}$ & 370 & $\begin{array}{l}3 \mathrm{~mm} \text { in maximal } \\
\text { diameter }\end{array}$ & 13 & 5 \\
\hline $\begin{array}{l}\text { Miyauchi, et al. }{ }^{20)} \\
(2018)^{*}\end{array}$ & Japan & $\begin{array}{l}<10 \mathrm{~mm} \text { in size } \\
\text { PTC (cytology) }\end{array}$ & $\begin{array}{l}10.1 \text { years } \\
(1.57-13.5)\end{array}$ & 169 & $\begin{array}{l}3 \mathrm{~mm} \text { in maximal } \\
\text { diameter }\end{array}$ & 7 & NR \\
\hline $\begin{array}{l}\text { Sakai, et al. }{ }^{18)} \\
(2019)^{*}\end{array}$ & Japan & $\begin{array}{l}<10 \mathrm{~mm} \text { in size } \\
\text { PTC (cytology) }\end{array}$ & $\begin{array}{l}7.3 \text { years } \\
(0.5-25)\end{array}$ & 360 & $\begin{array}{l}3 \mathrm{~mm} \text { in maximal } \\
\text { diameter }\end{array}$ & 29 & 3 \\
\hline & & $\begin{array}{l}10 \mathrm{~mm}<\text { size }<16 \mathrm{~mm} \\
\text { PTC (cytology) }\end{array}$ & $\begin{array}{l}7.9 \text { years } \\
(1-17)\end{array}$ & 61 & & 4 & 2 \\
\hline
\end{tabular}

*analysis of different parameter from same cohort. LNM, lymph node metastasis; PTC, papillary thyroid carcinoma; NR, not reported 

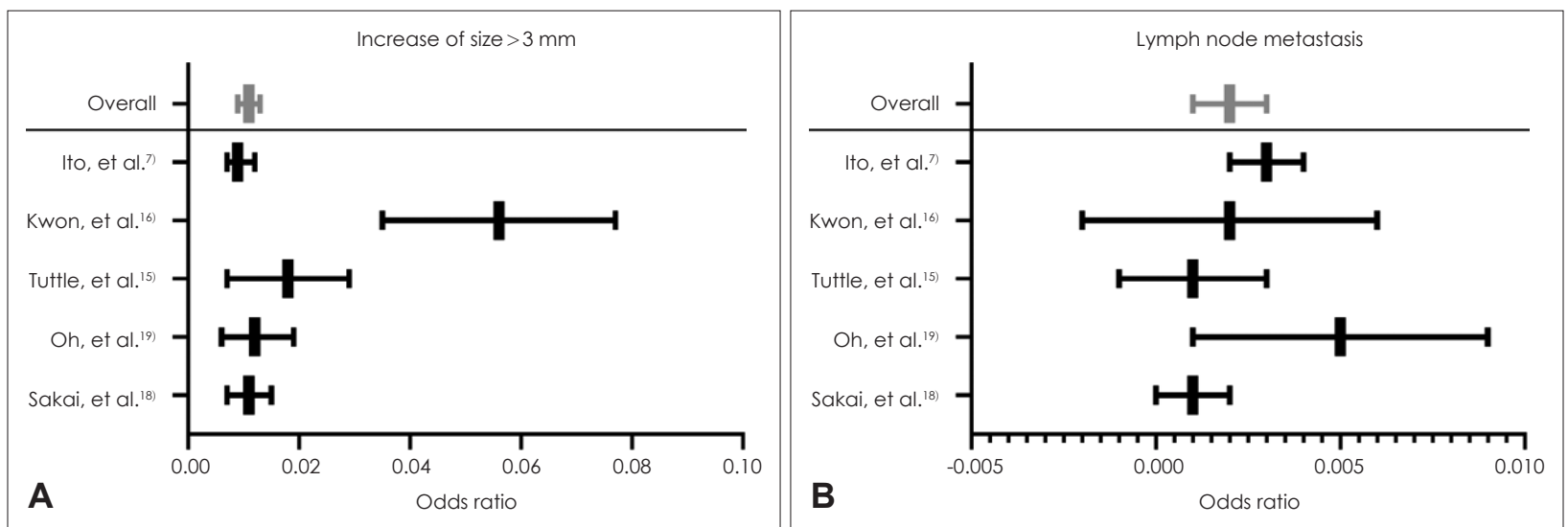

Fig. 2. Proportional meta-analysis of size increase over $3 \mathrm{~mm}(\mathrm{~A})$ and newly detected lymph node metastasis (B). Odds ratio of size increase more than $3 \mathrm{~mm}$ and newly detected lymph node metastasis was $0.011(\mathrm{~A})$ and $0.002(\mathrm{~B})$.

Table 2. Age-related data of included studies

\begin{tabular}{|c|c|}
\hline Author (year) & Size enlargement \\
\hline \multirow[t]{3}{*}{ Ito, et al.") (2014) } & $<40$ years: $5.9 \%$ \\
\hline & $40-59$ years: $5.7 \%$ \\
\hline & $\geq 60$ years: $2.2 \%$ \\
\hline \multirow[t]{2}{*}{ Sugitani, et al. ${ }^{14)}(2014)$} & Size enlargement $(+): 52.4 \pm 2.3$ \\
\hline & Size enlargement (-): $54.9 \pm 2.3$ \\
\hline \multirow[t]{2}{*}{ Kwon, et al. ${ }^{16)}(2017)$} & Size enlargement $(+): 48.6 \pm 5.1$ \\
\hline & Size enlargement (-): $51.7 \pm 5.4$ \\
\hline \multirow[t]{2}{*}{ Tuttle, et al. ${ }^{15)}(2017)$} & Size enlargement $(+): 41.8 \pm 9.6$ \\
\hline & Size enlargement (-): $52.4 \pm 15.0$ \\
\hline \multirow[t]{2}{*}{ Oh, et al. ${ }^{19)}(2018)$} & $<45$ years: $40.7 \%$ \\
\hline & $\geq 45$ years: $59.3 \%$ \\
\hline \multirow[t]{2}{*}{ Miyauchi, et al. ${ }^{20)}$ (2018) } & Size enlargement $(+): 50.5 \pm 10.4$ \\
\hline & Size enlargement (-): $53.8 \pm 15.9$ \\
\hline \multirow[t]{2}{*}{ Sakai, et al. ${ }^{18)}$ (2019) } & Size enlargement $(+): 49.5 \pm 6.2$ \\
\hline & Size enlargement (-): $54.7 \pm 10.8$ \\
\hline
\end{tabular}

\section{Incidence of size increase}

In all studies, the criteria to discontinue active surveillance and change the management strategy to surgery was a size increase of over $3 \mathrm{~mm}$ (maximal diameter of tumor) and newly detected lymph node metastasis on follow-up ultrasonography. Five studies reported the prevalence of size increase and lymph node metastasis. Our proportional meta-analysis showed that the proportion of a size increase more than $3 \mathrm{~mm}$ was 0.011 person-year for papillary thyroid carcinoma (95\% CI: 0.009 to 0.013 ), and that of lymph node metastasis was 0.002 person-year for papillary thyroid carcinoma (95\% CI: 0.001 to 0.003 ) (Fig. 2).

\section{Association between age/gender/initial size and size increase}

Age-related data of all of the included studies are shown in
Table 2. Data for age and size increase were available in four studies for a total of 1067 individuals. The standardized mean difference between individuals with and without size increase was -0.63 (95\% CI: -1.00 to -0.27 ) (Fig. 3A). The overall prevalence of size growing in females was $9.6 \%$ (77 of 798), whereas the prevalence in males was $4.9 \%$ (9 of 143). However, gender did not appear to be a significant risk factor for size increase, with an odd ratio of 1.55 (95\% CI: 0.75 to 3.22) (Fig. 3B). We included three studies with 701 patients in the analysis of the correlation between initial tumor size and size increase, which showed that initial tumor size was also not a significant risk factor for size increase (odd ratio $-1.11,95 \% \mathrm{CI}$ : -2.38 to 0.17 ) (Fig. 3C).

\section{Association between thyroid-stimulating hormone (TSH) and size increase}

Four studies examined the correlation between TSH levels and size increases. Kim, et al. ${ }^{17)}$ reported that high serum TSH levels (larger than $2.50 \mathrm{mU} / \mathrm{L}$ ) were associated with the progression of papillary thyroid microcarcinoma during active surveillance, and patients with lower TSH levels showed the lowest tumor progression (volume increase of more than 50\%). Moreover, Ito, et al. ${ }^{7)}$ also reported the successful outcomes of young patients who received TSH suppression. None of the microcancers in young patients who underwent TSH suppression grew. However, other studies failed to show the effect of TSH levels on tumor growth suppression. Oh, et al. ${ }^{19)}$ reported that thyroxine treatment and Hashimoto's thyroiditis did not have a significant correlation with tumor size changes. Further, in a nonsurgical observation trial for thyroid cancer, Sugitani, et al. ${ }^{14)}$ reported that there was no significant association between TSH levels and tumor progression. 


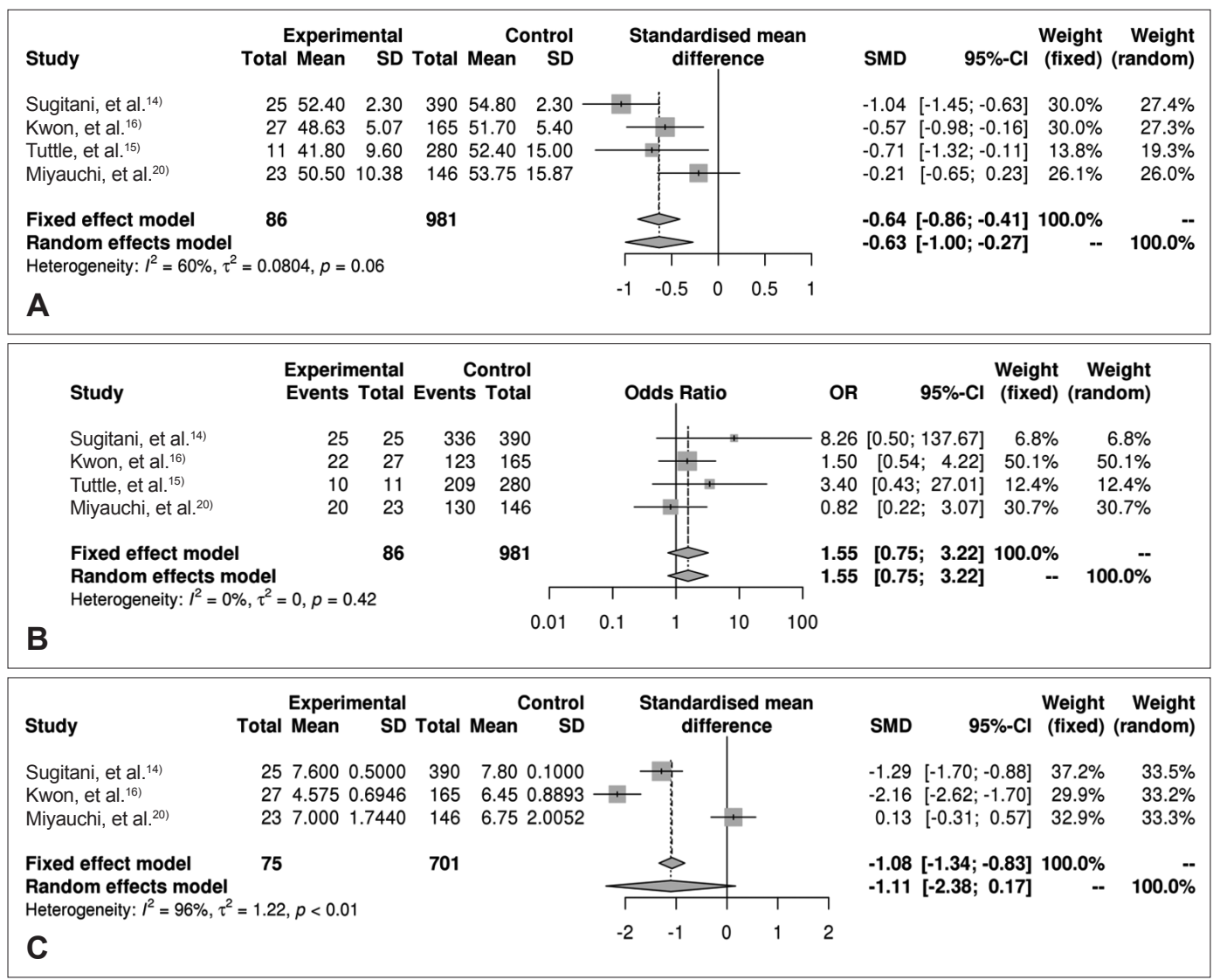

Fig. 3. Forest plots of studies reporting quantitative data of correlation between increase of tumor size and age (A), sex (B), initial size (C).

Table 3. Studies included in qualitative analysis for size increase during active surveillance

\begin{tabular}{|c|c|c|c|c|}
\hline Author (year) & Nationality & $\begin{array}{c}\text { Number of } \\
\text { patients }\end{array}$ & Parameters & Outcomes \\
\hline Fukuoka, et al. ${ }^{21)}(2016)$ & Japan & 384 & $\begin{array}{l}\text { Age, ultrasonographic } \\
\text { findings }\end{array}$ & $\begin{array}{l}\text { 1. Calcification is stronger and vascularity is weaker } \\
\text { in older patients } \\
\text { 2. Consolidation of calcification and loss of } \\
\text { vascularity is associated with non-progression }\end{array}$ \\
\hline Kim, et al. ${ }^{17)}$ (2018) & South Korea & 127 & TSH & $\begin{array}{l}\text { Sustained elevation of serum TSH levels is associated } \\
\text { with PTMC progression }\end{array}$ \\
\hline Miyauchi, et al. ${ }^{20)}(2018)$ & Japan & 1211 & Age & $\begin{array}{l}\text { The estimated lifetime disease progression is } \\
\text { associated with the age at presentation }\end{array}$ \\
\hline
\end{tabular}

TSH, thyroid-stimulating hormone; PTMC, papillary thyroid microcarcinoma

\section{Discussion}

Our study demonstrated that significant size increase in papillary thyroid cancer (more than $3 \mathrm{~mm}$ ) is significantly associated with age. Younger patients seemed to have higher rates of tumor size increase, although we found no association between gender or initial tumor size and the risk of tumor size increase. Proportional meta-analysis demonstrated that the proportion of size increase was 0.011 person-years, which means that 1 out of 100 patients presented with tumor size increases in a year. The proportion of newly detected lymph node metastasis was 0.002 person-years, which means that 1 in 500 patients presented with lymph node metastasis in a year.

Although we did not include these were in the quantitative analysis, several studies indicated that younger age is important contributor to tumor size increases during active surveillance (Table 3). Fukuoka, et al. ${ }^{21)}$ reported that papillary thyroid microcarcinoma in older patients showed a more indolent pattern. Reports from Kuma Hospital also indicated that over $10 \%$ of patients with an age at presentation less than 40 years 
showed a significant enlargement in tumor size, while less than $5 \%$ of those older than 60 years showed such changes. When they categorized patients into two groups in their study (age over and less than 50 years), there was no statistically significant differences. However, calcification on the initial and last sonographic examinations was important parameter associated with age. ${ }^{22)}$ Miyauchi, et al. ${ }^{20)}$ analyzed the estimated lifetime probability of tumor enlargement, and they concluded that those in their 20s, 30s, 40s, 50s, 60s, and 70s at presentation showed $46.0 \%, 30.7 \%, 24.3 \%, 14.8 \%, 8.9 \%$, and $2.8 \%$, respectively.

In females, estrogen and its receptors play a crucial role in the pathogenesis and progression of cancers, particularly breast cancer. $^{23,24)}$ However, the significance of estrogen in the progression of thyroid cancer remains unclear. A 3-4 times higher prevalence of differentiated thyroid cancer in females were reported by many epidemiological and clinical studies. In addition, the incidence of this tumor increases with the onset of puberty in females, ${ }^{25,26)}$ and pregnancy is significantly associated with its progression. ${ }^{27)}$ Therefore, females seem to be more susceptible to tumor growth than males. However, there are some reports that the risk for recurrence of thyroid cancer is higher in male than in female patients. Zahedi, et al. ${ }^{28)}$ reported that overall recurrence was $2.2 \%$ for female and $8.5 \%$ for male. Although our statistical analysis failed to show statistical significance, more studies are needed in this regard. Considering that the overall prevalence of tumor growth in females was $9.6 \%$ (77 of 798), whereas it was $4.9 \%$ (9 of 143) in males, analyses among a larger group of patients may reveal significant gender differences in tumor growth during active surveillance. Larger studies with age and gender categorization may thus show better results.

One of the characteristics of thyroid cancer is the relationship between tumor aggressiveness and prognosis. ${ }^{29)}$ Well-differentiated thyroid cancers have been reported to grow faster in young patients than in older patients and to be more frequently accompanied by distant metastasis. ${ }^{30)}$ Although these characteristics are not associated with prognosis, ${ }^{31)}$ young age seems to be associated with more rapid tumor growth and a more frequent requirement of surgical removal. Although dedifferentiation of well-differentiated thyroid cancer is a generally accepted concept for the development of anaplastic or poorly differentiated thyroid cancer, ${ }^{32,33)}$ these findings do not apply to papillary thyroid cancer, which does not seem to gradually acquire negative clinical characteristics, such as rapid tumor growth. ${ }^{34)}$
There is a wide use of thyroxine supplementation and the maintenance of lower TSH levels now during papillary thyroid cancer follow-up after ablation surgery. ${ }^{8)}$ Considering that currently, active surveillance is performed mainly for low-risk papillary thyroid cancer, the target TSH level can be below $2.0 \mathrm{mU} / \mathrm{L}$. Reports on the association of tumor size increases with TSH levels have varied according to the measurement methods used. When we use volume to evaluate tumor size, TSH levels were significantly associated with tumor growth, whereas there was no correlation between TSH levels and tumor growth when the tumor size was measured in terms of maximal diameter. As discussed by Tuttle, et al., ${ }^{15)}$ active surveillance management requires the availability of specialized and highly skilled radiologists. Considering that the size of the tumor is small and diameter measurement can be subjective, tumor volume may be a more sensitive parameter. Choi, et al. ${ }^{35)}$ reported that any differences smaller than $13.1 \%$ and $7.3 \%$ for volume and maximum diameter, respectively, measured using ultrasonography for well-defined thyroid nodules $>1 \mathrm{~cm}$ should not be considered real size changes. They also reported that the mean inter-observer difference for measuring the nodule volume was $-1.6 \%$, while the mean inter-observer difference was $-0.6 \%$ for the maximum nodule diameter.

Although inter-observer variation is not significantly different, anecdotal evidence suggests that tumor size in papillary thyroid cancer fluctuates during follow-up, although no data on this has been published to-date. However, in clinical settings, volume measurement tends to be time-consuming and inconvenient when compared to maximal diameter measurement, which is where discrepancies might arise from. However, it remains an open question which of the evaluations on maximal diameter or on tumor volume is better. Actually, evaluation on volume is seemingly sensitive and better, but size/volume of papillary thyroid microcarcinoma (PTMC) often fluctuates. Studies published to date set tumor enlargement at $50 \%$ volume increase, which is too early. Moreover, life-threatening events occurred in none of the patients with PTMC in Japan (evaluation on maximal diameter). ${ }^{7,20)}$ Although we think that maximal diameter is currently better, further studies should be performed in this regard to confirm the best way of tumor measurement during active surveillance.

Papillary thyroid cancer management is associated with significant medical costs, which are a very crucial individual and societal concern. Lubitz, et al. ${ }^{36)}$ warned that the overall cost of well-differentiated thyroid cancer care in the United States might exceed US $\$ 3.5$ billion by 2030 , based on current 
trends in the incidence of this cancer. Three studies focused on the active surveillance of thyroid cancer. Lang and Wong ${ }^{37)}$ performed a comparative study of early surgical management and non-surgical management for incidental papillary thyroid microcarcinoma. They concluded that the non-surgical approach was cost-saving up to 16 years from diagnosis, and remained cost-effective from 17 years onwards. Oda, et al. ${ }^{38)}$ also reported that the total cost of 10 years of immediate surgery was 4.1 times higher than that of active surveillance. In contrast, Venkatesh, et al. ${ }^{39)}$ reported that in patients who would associate non-operative management with at least a moderate decline in quality of life, hemithyroidectomy was cost-effective. However, current studies are complicated, and the analysis of total thyroidectomy is lacking. Although healthcare costs are a considerable burden for countries worldwide, estimates regarding thyroid cancer treatment are different in different places due to the particulars of systems and insurance structures and is incomparable.

This study has some limitations. First, the number of articles included in the quantitative analysis of risk factors in tumor size increase during active surveillance is small. This prevented a subgroup or sensitivity analysis in the present study. Secondly, there was publication bias in the sample of studies included (Supplementary Fig. 1). Moreover, despite the small number of studies, criteria for active surveillance and duration of follow-up were not unified. In addition, limited regions were used in northeast Asia except for one study. Thirdly, study-level bias might be present; as ultrasonographic tests are important in decision-making during active surveillance, treatment recommendations depend on the clinical judgment of each radiologist, implying that studies with different radiologists might have considerable different thresholds. Lastly, we cannot present a significant cut-off value of age. To confirm the cut-off value of age, further studies with larger cohorts are mandatory.

In conclusion, our study shows that active surveillance can carefully be applied for selected patients. It may be applied more cautiously for younger patients although it is not contraindicated. Further, there are need for large-cohort studies to elucidate the link between gender and TSH.

\section{Supplementary Materials}

The Data Supplement is available with this article at https://doi. org/10.3342/kjorl-hns.2021.00990.

\section{Acknowledgments}

We appreciate Professor Yasuhuro Ito from Kuma Hospital for reviewing and commenting on our manuscript.

\section{Author Contribution}

Conceptualization: Doh Young Lee. Data curation: Doh Young Lee, Pilkeun Jang. Formal analysis: Doh Young Lee, Pilkeun Jang. Methodology: Doh Young Lee. Writing — original draft: Doh Young Lee. Writing — review \& editing: Doh Young Lee, Pilkeun Jang.

\section{ORCIDs}

Doh Young Lee https://orcid.org/0000-0003-1590-8559

Pilkeun Jang https://orcid.org/0000-0002-3339-8735

\section{REFERENCES}

1) Canaris GJ, Manowitz NR, Mayor G, Ridgway EC. The Colorado thyroid disease prevalence study. Arch Intern Med 2000;160(4): 526-34.

2) Jung KW, Park S, Kong HJ, Won YJ, Lee JY, Seo HG, et al. Cancer statistics in Korea: Incidence, mortality, survival, and prevalence in 2009. Cancer Res Treat 2012;44(1):11-24.

3) Cho BY, Choi HS, Park YJ, Lim JA, Ahn HY, Lee EK, et al. Changes in the clinicopathological characteristics and outcomes of thyroid cancer in Korea over the past four decades. Thyroid 2013; 23(7):797-804.

4) Kent WD, Hall SF, Isotalo PA, Houlden RL, George RL, Groome PA. Increased incidence of differentiated thyroid carcinoma and detection of subclinical disease. CMAJ 2007;177(11):1357-61.

5) Pathak KA, Leslie WD, Klonisch TC, Nason RW. The changing face of thyroid cancer in a population-based cohort. Cancer Med 2013;2(4):537-44.

6) Enewold L, Zhu K, Ron E, Marrogi AJ, Stojadinovic A, Peoples GE, et al. Rising thyroid cancer incidence in the United States by demographic and tumor characteristics, 1980-2005. Cancer Epidemiol Biomarkers Prev 2009;18(3):784-91.

7) Ito Y, Miyauchi A, Kihara M, Higashiyama T, Kobayashi K, Miya A. Patient age is significantly related to the progression of papillary microcarcinoma of the thyroid under observation. Thyroid 2014; 24(1):27-34.

8) Haugen BR, Alexander EK, Bible KC, Doherty GM, Mandel SJ, Nikiforov YE, et al. 2015 American Thyroid Association management guidelines for adult patients with thyroid nodules and differentiated thyroid cancer: The American Thyroid Association guidelines task force on thyroid nodules and differentiated thyroid cancer. Thyroid 2016;26(1):1-133.

9) Alhashemi A, Goldstein DP, Sawka AM. A systematic review of primary active surveillance management of low-risk papillary carcinoma. Curr Opin Oncol 2016;28(1):11-7.

10) Moher D, Liberati A, Tetzlaff J, Altman DG; The PRISMA Group. Preferred reporting items for systematic reviews and metaanalyses: The PRISMA statement. PLoS Med 2009;6(7):e1000097.

11) Liberati A, Altman DG, Tetzlaff J, Mulrow C, Gøtzsche PC, Ioannidis JP, et al. The PRISMA statement for reporting systematic reviews and meta-analyses of studies that evaluate healthcare interventions: Explanation and elaboration. BMJ 2009;339:b2700.

12) Higgins JP, Thompson SG, Deeks JJ, Altman DG. Measuring inconsistency in meta-analyses. BMJ 2003;327(7414):557-60.

13) Sterne JA, Gavaghan D, Egger M. Publication and related bias in meta-analysis: Power of statistical tests and prevalence in the literature. J Clin Epidemiol 2000;53(11):1119-29.

14) Sugitani I, Fujimoto Y, Yamada K. Association between serum thyrotropin concentration and growth of asymptomatic papillary thyroid microcarcinoma. World J Surg 2014;38(3):673-8.

15) Tuttle RM, Fagin JA, Minkowitz G, Wong RJ, Roman B, Patel S, et al. Natural history and tumor volume kinetics of papillary thyroid cancers during active surveillance. JAMA Otolaryngol Head Neck 
Surg 2017;143(10):1015-20.

16) Kwon H, Oh HS, Kim M, Park S, Jeon MJ, Kim WG, et al. Active surveillance for patients with papillary thyroid microcarcinoma: A single center's experience in Korea. J Clin Endocrinol Metab 2017; 102(6):1917-25.

17) Kim HI, Jang HW, Ahn HS, Ahn S, Park SY, Oh YL, et al. High serum TSH level is associated with progression of papillary thyroid microcarcinoma during active surveillance. J Clin Endocrinol Metab 2018;103(2):446-51.

18) Sakai T, Sugitani I, Ebina A, Fukuoka O, Toda K, Mitani H, et al. Active surveillance for T1bN0M0 papillary thyroid carcinoma. Thyroid 2019;29(1):59-63.

19) Oh HS, Ha J, Kim HI, Kim TH, Kim WG, Lim DJ, et al. Active surveillance of low-risk papillary thyroid microcarcinoma: A multi-center cohort study in Korea. Thyroid 2018;28(12):1587-94.

20) Miyauchi A, Kudo T, Ito Y, Oda H, Sasai H, Higashiyama T, et al. Estimation of the lifetime probability of disease progression of papillary microcarcinoma of the thyroid during active surveillance. Surgery 2018;163(1):48-52.

21) Fukuoka O, Sugitani I, Ebina A, Toda K, Kawabata K, Yamada K. Natural history of asymptomatic papillary thyroid microcarcinoma: Time-dependent changes in calcification and vascularity during active surveillance. World J Surg 2016;40(3):529-37.

22) Miyauchi A. Clinical trials of active surveillance of papillary microcarcinoma of the thyroid. World J Surg 2016;40(3):516-22.

23) Cho MA, Lee MK, Nam KH, Chung WY, Park CS, Lee JH, et al. Expression and role of estrogen receptor alpha and beta in medullary thyroid carcinoma: Different roles in cancer growth and apoptosis. J Endocrinol 2007;195(2):255-63.

24) Derwahl M, Nicula D. Estrogen and its role in thyroid cancer. Endocr Relat Cancer 2014;21(5):T273-83.

25) Farahati J, Bucsky P, Parlowsky T, Mäder U, Reiners C. Characteristics of differentiated thyroid carcinoma in children and adolescents with respect to age, gender, and histology. Cancer 1997;80(11):2156-62.

26) Li N, Du XL, Reitzel LR, Xu L, Sturgis EM. Impact of enhanced detection on the increase in thyroid cancer incidence in the United States: Review of incidence trends by socioeconomic status within the surveillance, epidemiology, and end results registry, 19802008. Thyroid 2013;23(1):103-10.

27) Messuti I, Corvisieri S, Bardesono F, Rapa I, Giorcelli J, Pellerito $\mathrm{R}$, et al. Impact of pregnancy on prognosis of differentiated thyroid cancer: Clinical and molecular features. Eur J Endocrinol 2014;
170(5):659-66.

28) Zahedi A, Bondaz L, Rajaraman M, Leslie WD, Jefford C, Young $\mathrm{JE}$, et al. Risk for thyroid cancer recurrence is higher in men than in women independent of disease stage at presentation. Thyroid 2020;30(6):871-7.

29) Takano T. Natural history of thyroid cancer. Endocr J 2017;64(3): 237-44.

30) Kowalski LP, Gonçalves Filho J, Pinto CA, Carvalho AL, de Camargo B. Long-term survival rates in young patients with thyroid carcinoma. Arch Otolaryngol Head Neck Surg 2003;129(7):746-9.

31) Ito $Y$, Miyauchi A, Ito M, Yabuta T, Masuoka H, Higashiyama T, et al. Prognosis and prognostic factors of differentiated thyroid carcinoma after the appearance of metastasis refractory to radioactive iodine therapy. Endocr J 2014;61(8):821-4.

32) Lee DY, Won JK, Lee SH, Park DJ, Jung KC, Sung MW, et al. Changes of clinicopathologic characteristics and survival outcomes of anaplastic and poorly differentiated thyroid carcinoma. Thyroid 2016;26(3):404-13.

33) Lee DY, Won JK, Choi HS, Park DJ, Jung KC, Sung MW, et al. Recurrence and survival after gross total removal of resectable undifferentiated or poorly differentiated thyroid carcinoma. Thyroid 2016;26(9):1259-68

34) Takano T, Amino N. Fetal cell carcinogenesis: A new hypothesis for better understanding of thyroid carcinoma. Thyroid 2005;15(5): 432-8.

35) Choi YJ, Baek JH, Hong MJ, Lee JH. Inter-observer variation in ultrasound measurement of the volume and diameter of thyroid nodules. Korean J Radiol 2015;16(3):560-5.

36) Lubitz CC, Kong CY, McMahon PM, Daniels GH, Chen Y, Economopoulos KP, et al. Annual financial impact of welldifferentiated thyroid cancer care in the United States. Cancer 2014;120(9):1345-52.

37) Lang BH, Wong CK. A cost-effectiveness comparison between early surgery and non-surgical approach for incidental papillary thyroid microcarcinoma. Eur J Endocrinol 2015;173(3):367-75.

38) Oda H, Miyauchi A, Ito Y, Sasai H, Masuoka H, Yabuta T, et al. Comparison of the costs of active surveillance and immediate surgery in the management of low-risk papillary microcarcinoma of the thyroid. Endocr J 2017;64(1):59-64.

39) Venkatesh S, Pasternak JD, Beninato T, Drake FT, Kluijfhout WP, Liu C, et al. Cost-effectiveness of active surveillance versus hemithyroidectomy for micropapillary thyroid cancer. Surgery 2017;161(1):116-26. 


\begin{tabular}{|c|c|c|}
\hline Section/topic & \# & Checklist item \\
\hline Title & & Identify the report as a systematic review, meta-analysis, or both. \\
\hline \multicolumn{3}{|l|}{ Abstract } \\
\hline Structured summary & & $\begin{array}{l}\text { Provide a structured summary including, as applicable: background; objectives; data sources; study eligibility criteria, } \\
\text { participants, and interventions; study appraisal and synthesis methods; results; limitations; conclusions and implications of } \\
\text { key findings; systematic review registration number. }\end{array}$ \\
\hline
\end{tabular}

\section{Introduction}

Rationale

Objectives

\section{Methods}

Protocol and registration

Eligibility criteria

Information source

Search

Study selection

Data collection process

Data items

Risk of bias in individual

studies

Summary measures

Synthesis of results

Risk of bias across studies 15 Specify any assessment of risk of bias that may affect the cumulative evidence (e.g., publication bias, selective reporting within studies).

Additional analyses

16 Describe methods of additional analyses (e.g., sensitivity or subgroup analyses, meta-regression), if done, indicating which were pre-specified.

\section{Results}

Study selection

Study characteristics

17 Give numbers of studies screened, assessed for eligibility, and included in the review, with reasons for exclusions at each stage, ideally with a flow diagram.

18 For each study, present characteristics for which data were extracted (e.g., study size, PICOS, follow-up period) and provide the citations.

Risk of bias within studies 19 Present data on risk of bias of each study and, if available, any outcome level assessment (see item 12).

Results of individual

studies

20 For all outcomes considered (benefits or harms), present, for each study: (a) simple summary data for each intervention group (b) effect estimates and confidence intervals, ideally with a forest plot.

Synthesis of results 21 Present results of each meta-analysis done, including confidence intervals and measures of consistency.

Risk of bias across studies 22 Present results of any assessment of risk of bias across studies (see ltem 15).

Additional analysis $\quad 23$ Give results of additional analyses, if done (e.g., sensitivity or subgroup analyses, meta-regression [see Item 16]).

\section{Discussion}

Summary of evidence

Limitations

Conclusions

Funding

For more information, visit: www.prisma-statement.org. Adapted from Moher, et al. PLoS Med 2009;6(7):e1000097 
Supplementary Table 2. Searching strategy and results

\begin{tabular}{ccc}
\hline Database & \multicolumn{1}{c}{ Terms } & Results \\
\hline MEDLINE & "thyroid" AND ("surveillance" OR "observation") & 4401 \\
EMBASE & "thyroid" AND ("surveillance" OR "observation") & 7377 \\
\hline
\end{tabular}


Supplementary Table 3. Newcastle-Ottawa scale of bias risk for the included studies

\begin{tabular}{|c|c|c|c|c|c|c|c|c|c|}
\hline Study & $\begin{array}{c}\text { Adequate case } \\
\text { definition }\end{array}$ & $\begin{array}{c}\text { Representativeness } \\
\text { of cases }\end{array}$ & $\begin{array}{l}\text { Selection } \\
\text { of controls }\end{array}$ & $\begin{array}{l}\text { Definition } \\
\text { of controls }\end{array}$ & Comparability & $\begin{array}{l}\text { Ascertainment } \\
\text { of exposure }\end{array}$ & $\begin{array}{c}\text { Method of } \\
\text { ascertainment }\end{array}$ & $\begin{array}{c}\text { Nonresponse } \\
\text { rate }\end{array}$ & Score/10 \\
\hline (to, et al. & $*$ & $*$ & $*$ & $*$ & $*$ & $*$ & $*$ & & 7 \\
\hline Sugitani, et al. ${ }^{13)}$ & * & * & $*$ & $*$ & $*$ & * & * & & 7 \\
\hline Kwon, et al. ${ }^{15)}$ & $*$ & $*$ & $*$ & * & $* *$ & * & $*$ & & 8 \\
\hline Tuttle, et al. ${ }^{14)}$ & * & $*$ & $*$ & $*$ & $* *$ & * & * & & 8 \\
\hline Oh, et al. ${ }^{18)}$ & $*$ & $*$ & $*$ & * & $*$ & * & $*$ & & 7 \\
\hline Miyauchi, et al. ${ }^{21)}$ & $*$ & $*$ & $*$ & $*$ & $*$ & $*$ & $*$ & & 7 \\
\hline Sakai, et al. ${ }^{17)}$ & * & $*$ & $*$ & * & $* *$ & $*$ & $*$ & & 8 \\
\hline
\end{tabular}

Asterisks are the star rating as per the Newcastle-Ottawa Scale 


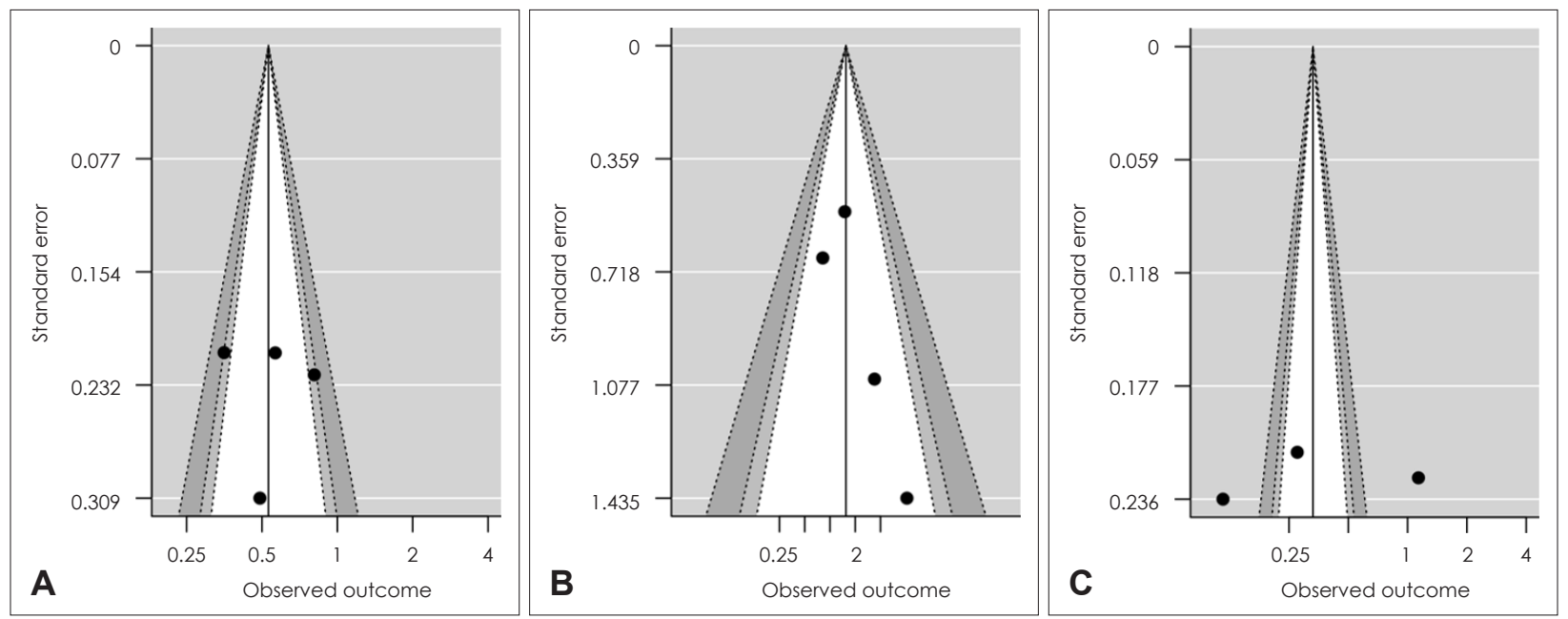

Supplementary Fig. 1. Publication bias of studies reporting quantitative data of correlation between increase of tumor size and age (A), sex (B), initial size (C). 